\title{
New Chemical Compounds Isolated from the Stem Bark of Talipariti Elatum Sw. in Cuba
}

\author{
José González ${ }^{1 *}$, Armando Cuéllar ${ }^{1}$, Julio Pérez ${ }^{2}$, Max Monan $^{3}$, Enrique Gómez ${ }^{1}$ \\ ${ }^{I}$ Department of Pharmacy, Faculty of Pharmacy and Foods, Havana University \\ ${ }^{2}$ National Center of Toxicology, Military Hospital "Carlos J. Finlay", Havana \\ ${ }^{3}$ ARVARNAM, Martinica, France \\ *Corresponding Author: José González, Department of Pharmacy, Faculty of Pharmacy and Foods, \\ Havana University, Cuba

\begin{abstract}
Stem Bark of Talipariti elatum Sw. was extracted by Soxhlet with toluene. After extracts concentration, the sample was processed with $\mathrm{CHCl}_{3}$ that allow getting a precipitate. The phytochemical studies of stem bark of Talipariti elatum have led to the identification of two triterpenoids: friedelin and fridelinol, an esterified triterpenoid, three alcohols and one aromatic acid. The structures of these compounds were identified by analysis of GC/MS data and comparison with values of literature.
\end{abstract}

Keywords: Talipariti elatum, Toluene, Soxhlet, Triterpenoids, GC/MS.

\section{INTRODUCTION}

Talipariti elatum S.w Fryxell (Malvaceae), a tree with a wide distribution in Cuba, that growth in any type of soil particularly in swanpyones. It can get about $25 \mathrm{~m}$ of height. It shows peciolated leaves, to mentose-velvet like and heart-shaped at the basis. The flowers are big, yellow flower leaves that become reddish when old. The flowers are used as appetitive, emollient, sudorific and as excellent pectoral combined with the flowers of Hibiscus rosa-sinensis. The mixture is used in traditional medicine as expectorant and antasthmatic (Roig, 2014). It is reported that flowers of T. elatum contains flavonoids (quercetin and rutin), sugars, phenols and tannins, triterpens and steroids and saponins (Acosta \& Rodríguez, 2006), although the plants' composition has not been determined in detail so far.Gossypetin -3'-O-glucoside was isolated for the first time from the flowers of the plant in Martinic Island by maceration with methanol $(24 \mathrm{~h})$, and Soxhlet extraction with methanol, ethyl acetate and 1,2-dimethoxyethane as solvents(François-Haugrin et al., 2015) and in Cuba in 2016 (Yaque et al., 2016).

Gas chromatography coupled with mass spectrometry (GC-MS) in particular is a fast and accurate method widely applied in diagnostics, functional genomics and for screening purposes. Following solvent extraction and derivatization, hundreds of metabolites from different chemical groups can be characterized in one analytical run. Gas chromatography (GC) in particular is characterized by sensitivity and reliability of separations and detection of complex sample mixtures (Wang et al. 2015). Coupling with mass spectrometry (MS) provides highly robust analysis platforms compared to liquid chromatography (LC-MS) and allows for the identification of compounds based on the use of commercially or publicly available MS libraries and resources in combination with retention time index (RI) data (Rohloff, 2015). The aim of this research was to characterize the chemical components present in the toluene extracts of stem bark from T. elatum S.w.

\section{Material AND MethodS}

\subsection{Plant Material}

Stem bark was collected in January 2017 in the gardens of the Faculty of Pharmacy and Foods at Havana University, and identified at the herbarium of National Botany Garden of Havana, where the voucher specimen no. HAJB 82587 has been deposited. Specimen is registered as Talipariti elatum Sw. (Fryxell) Malvaceae (Sin. Hibiscus elatus Sw). 


\subsection{Extract and Samples Preparation}

The sample was cleaned twice with distilled water. Then the sample was dry in an oven with controlled temperature at $40{ }^{\circ} \mathrm{C}$ during 5 days. After dried, the sample was pulverized to powder using a mechanical grinder. The particles were uniformed using a sieve $(1 \mathrm{~mm})$ (Fig. 1). The powder was stored in an air-dried packet. The extracts were prepared with the ground material $(60 \mathrm{~g})$ without screen extracted in a Soxhlet apparatus with $675 \mathrm{~mL}$ of toluene during 16 hours. The extracts were concentrated and evaporated under vacuum to $200 \mathrm{~mL}$ at $120 \mathrm{rpm}$, a temperature of $70^{\circ} \mathrm{C}$ and 500 mbar.

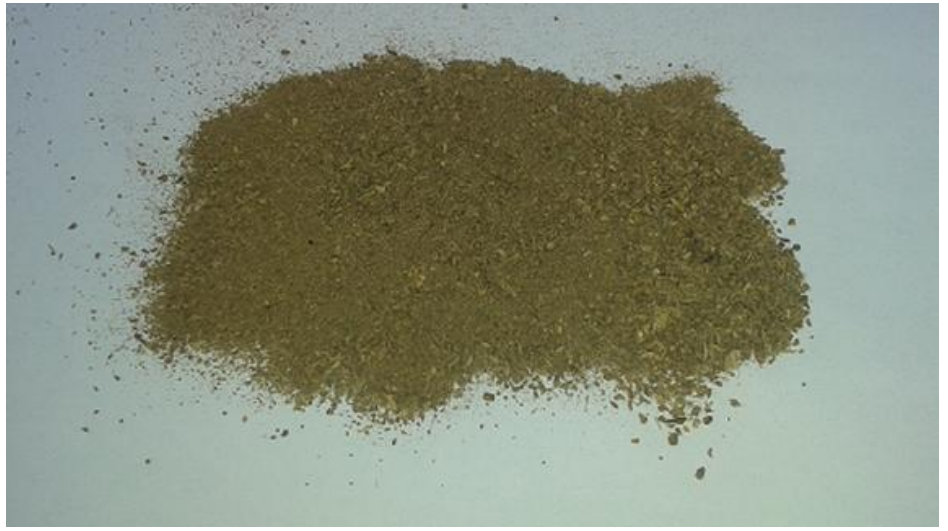

Fig.1. Powdered drug

After concentration the extract was dissolved in $20 \mathrm{~mL}$ of chloroform and added slowly over $100 \mathrm{~mL}$ of a mixture of ketone-methanol (1:1). Trying to rich a second dissolution in chloroform a cream yellow precipitate was collected by filtration on a filter of porosity 3, and dried in the dark at room temperature. After 24 hours another cream yellow precipitate appear and was recovered and purified under same conditions (Fig. 2). That product was used in characterization process.

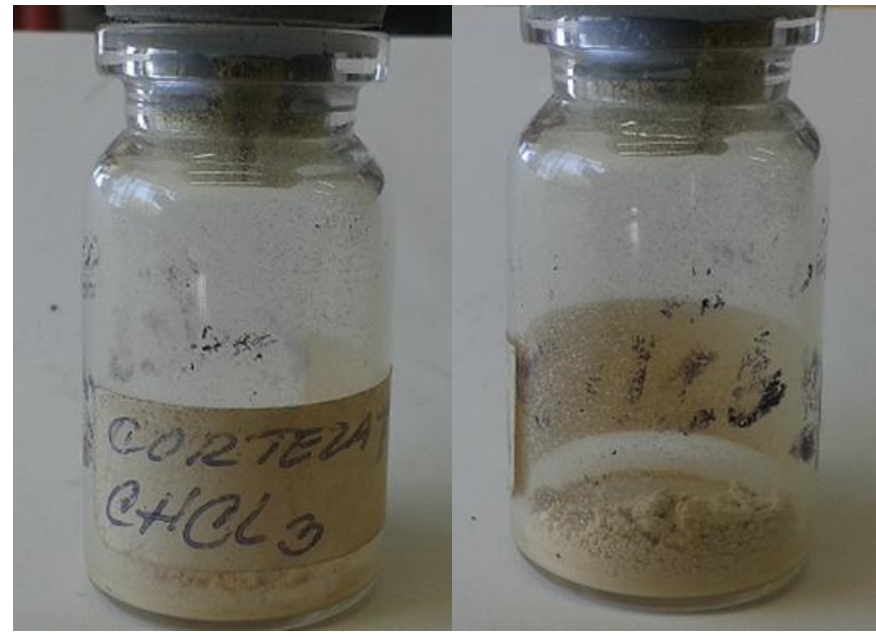

Fig. 2. Precipitate insoluble in $\mathrm{CHCl}_{3}$.

\subsection{Procedures, Instrumentation and Parameters}

The sample were subjected to chromatographic analysis in equipment GC/MS, brand Shimadzu QP2010, equipped with a splitter split/splitless. With a BP5 $(30 \mathrm{~m} \times 0.25 \mathrm{~mm} \times 0.25$ microns $)$ capillary column under the following chromatographic conditions: Helium gas carrier obtained by electron impact fragments to a power of $70 \mathrm{eV}$ rate of $1.2 \mathrm{~mL} / \mathrm{min}, 1: 50$ split flow and the volume of injected sample of $1 \mathrm{ul}$. Programmed oven temperature: initial temperature was $70^{\circ} \mathrm{C}$ with a heating ramp of $10^{\circ} \mathrm{C} / \mathrm{min}$ to $300^{\circ} \mathrm{C}$ and remained stable at this temperature for 10 minutes. Subsequently the temperature was increased at a rate of $10^{\circ} \mathrm{C} /$ minute to $300^{\circ} \mathrm{C}$ for a total time of 78 minutes with an injector temperature $250^{\circ} \mathrm{C}$ and the interface temperature $300^{\circ} \mathrm{C}$. The compounds were analyzed using GC/MS NIST21 and NIST107 library and having into account the results obtained after phytochemical screening according with Gómez (2017). Silylation agent was N, O-bis (trimethylsilyl) trifluoroacetamide (BSTFA) CAS 25561-30-2 Lot: 0901-1 Macherey-Nagel GmbH \& C. KG. Chromatographic running was done twice, with and without BSTFA. 


\section{RESULTS AND DISCUSSION}

Chromatographic profile of both running showed the same amount of chemical components with few differences that corresponding to adduct formed in the derivatization process (Figures 3 and 4). For that reason the authors determined to analyze the sample without BSTFA and because of the most of compounds were found between 35 and 65 minutes in both cases (Fig. 5).

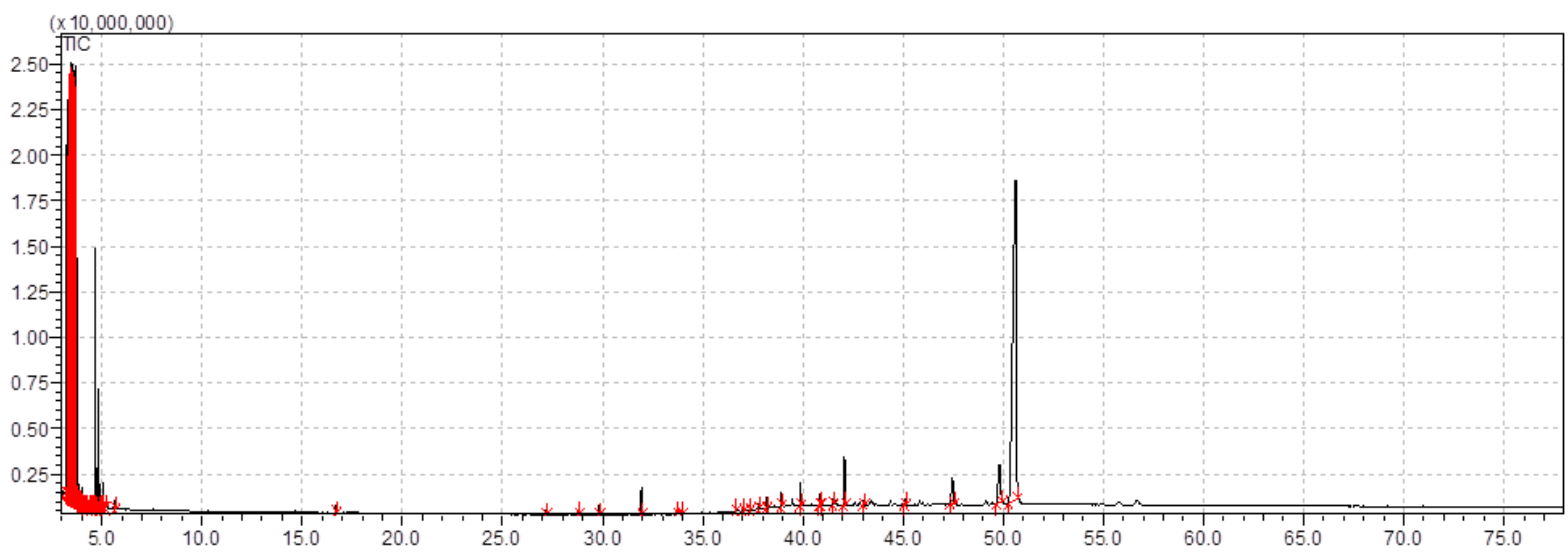

Fig. 3. Chromatographic profile of the sample with BSTFA.

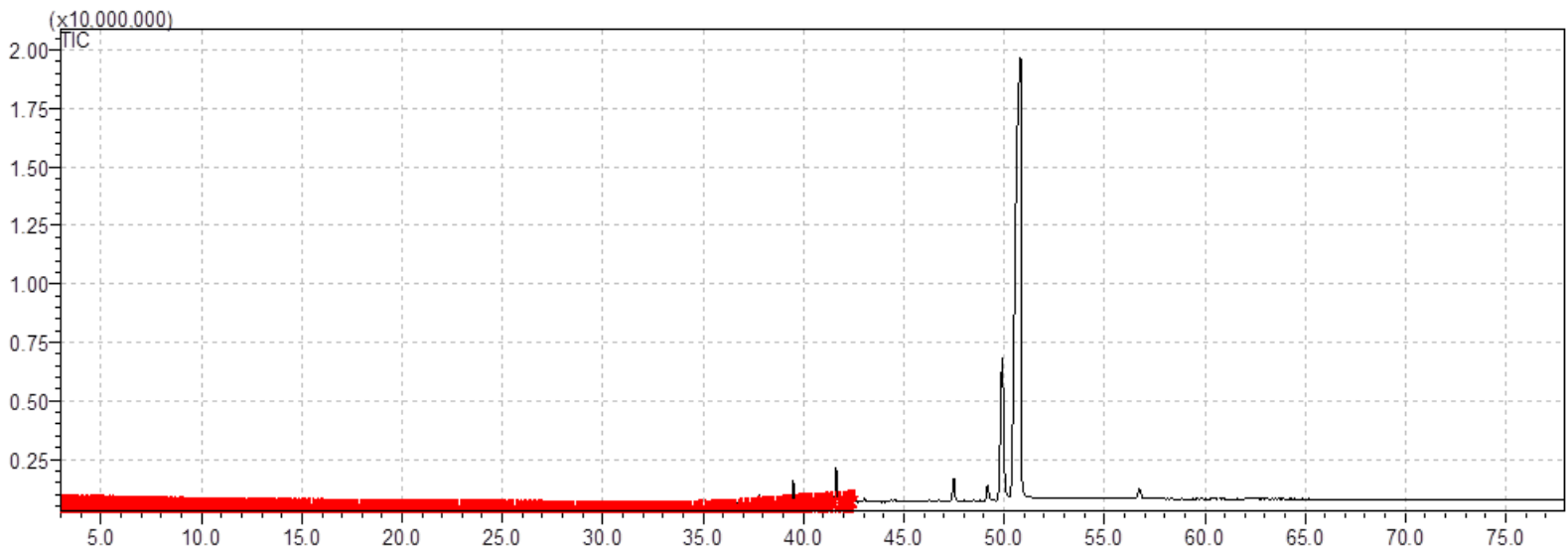

Fig.4. Chromatographic profile of the sample without BSTFA.

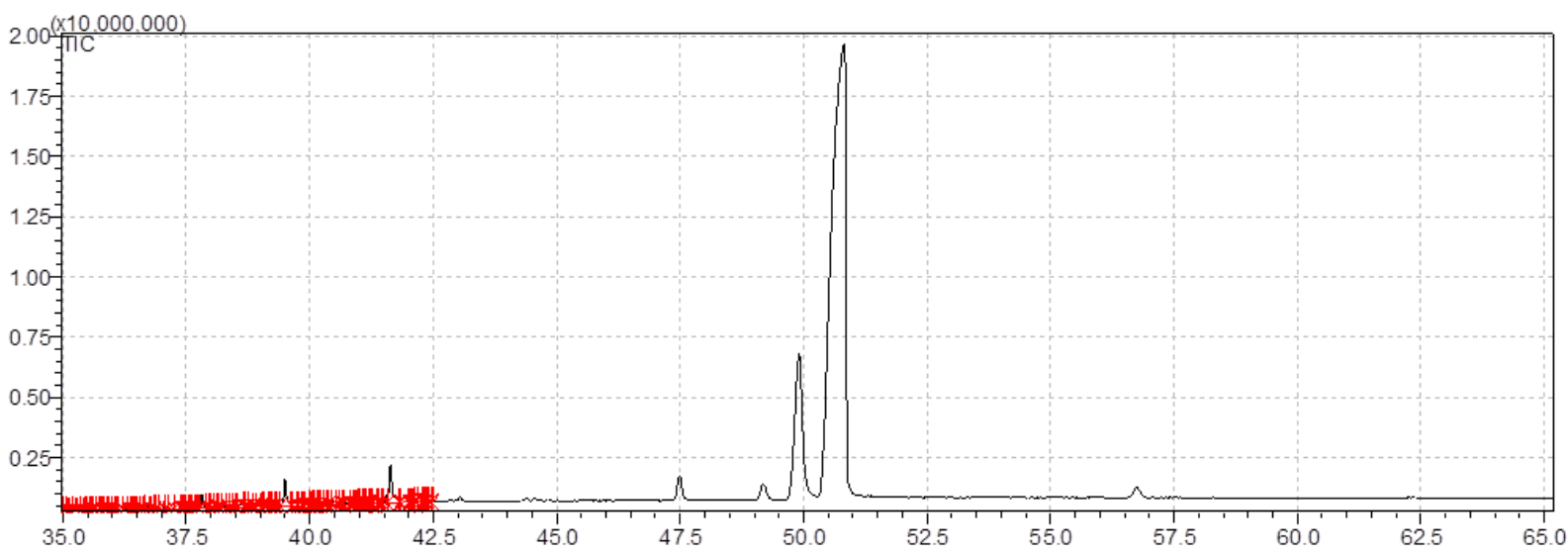

Fig. 5. Current chromatogram without BSTFA (Rt-35-65 min).

Only eight compounds were identified by GC/MS from the insoluble sample in $\mathrm{CHCl}_{3}$. The three first chemical metabolites are related with aliphatic alcohols with 27, 18 and 20 carbon atoms respectively: 1-Heptacosanol, 1,2-Octadecanediol and 1-Eicosanol. Another compound related with alcohols was identified as 1-Naphthalenepropanol,.alpha.-ethyldecahydro-.alpha.,5,5,8a-tetramethyl-2methylene-, [1S-[1.alpha. Three secondary metabolites stretchy related were identified as Acetic acid, 4,4a, 6b, 8a, 11, 11, 12b, 14a-octamethyl-3-oxodocosahydropicen-2-yl ester and two members of the Fridelane series: Friedooleanan-3-ol and Friedelin (Friedelan-3-one). The last component was identified as 4tert-Butylphenoxy-.alpha.-Propionic acid. Their corresponding acquired data are shown in Table 1. 
Table 1. GC/MS spectral data found in the solid sample of stem bark from T. elatum.

\begin{tabular}{|c|c|c|c|c|c|}
\hline No. & Rt (min) & Compound name & Mol. Form. & Mol. Weight & Base Peak \\
\hline 1 & 37.814 & 1-Heptacosanol & $\mathrm{C}_{27} \mathrm{H}_{56} \mathrm{O}$ & 396 & 43 \\
\hline 2 & 39.512 & 1,2-Octadecanediol & $\mathrm{C}_{18} \mathrm{H}_{38} \mathrm{O}_{2}$ & 286 & 57 \\
\hline 3 & 41.643 & 1-Eicosanol & $\mathrm{C}_{20} \mathrm{H}_{42} \mathrm{O}$ & 298 & 57 \\
\hline 4 & 47.510 & 1-Naphthalenepropanol & $\mathrm{C}_{20} \mathrm{H}_{36} \mathrm{O}$ & 292 & 137 \\
\hline 5 & 49.186 & Acetic acid, 4,4a, 6b... & $\mathrm{C}_{32} \mathrm{H}_{52} \mathrm{O}_{3}$ & 484 & 43 \\
\hline 6 & 49.931 & Friedooleanan-3-ol & $\mathrm{C}_{30} \mathrm{H}_{52} \mathrm{O}$ & 428 & 69 \\
\hline 7 & 50.769 & Friedelin & $\mathrm{C}_{30} \mathrm{H}_{50} \mathrm{O}$ & 426 & 69 \\
\hline 8 & 56.755 & 4-tert-Butylphenoxy.... & $\mathrm{C}_{13} \mathrm{H}_{18} \mathrm{O}_{3}$ & 222 & 207 \\
\hline
\end{tabular}

Friedooleanan-3-ol and Friedelin (Friedelan-3-one) showed the most prominent peaks indicating that they are the most abundant chemical components in the sample. According to Gomez 2017, there are evidences of the presence of triterpenes and steroids in the extracts of this part of the plant because the test with Liebermann-Burchard was positive (Zhu et al., 2016). It is the first time that both components are reported from the stem bark of Talipariti elatum in Cuba. The fragmentations patterns propose for both compounds are similar in general, due to the great coincidence in fragment ion peaks, although the molecular masses are different by two units.<smiles>C=CC1=CCCC2(C)CCC(C)(C)CC12</smiles>

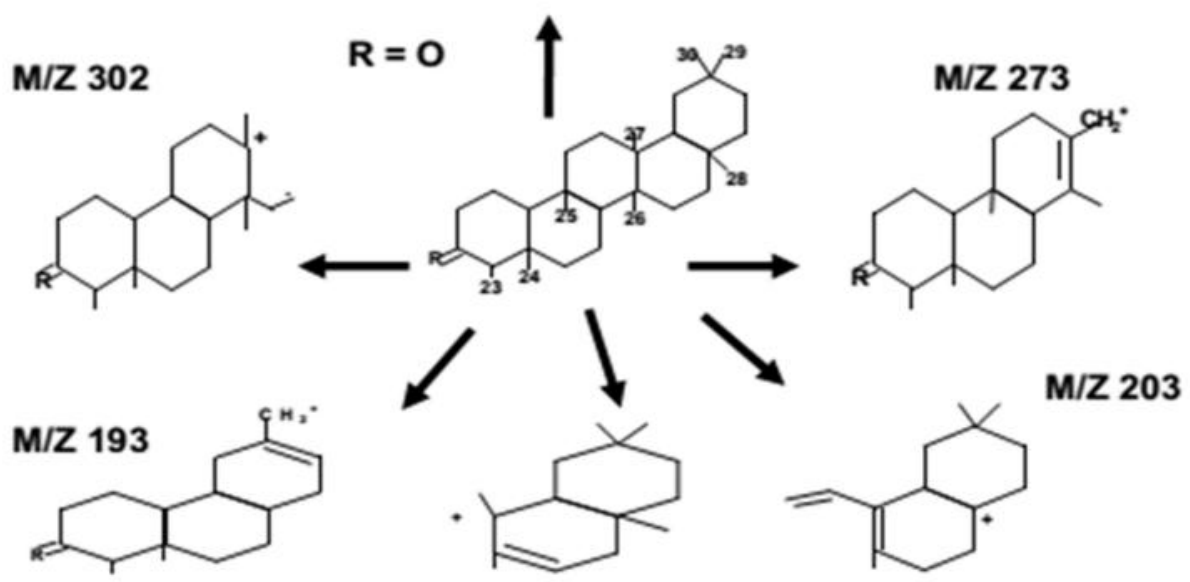

$M / Z 205$

Fig. 6. Proposal fragmentation patterns for Friedelan-3 $\beta$-ol and Friedelin.

\section{CONCLuSions}

GC/MS was used for the generation of chemical fingerprints and the identification of several compounds in T. elatum. The spectral analysis of the solid precipitate recovered from the toluene extract showed the majority of eight compounds. Among them, two pentaciclic triterpenoids were characterized in this part of the plant at the same time: Friedelan-3 $\beta$-ol and Friedelin-3-one for the first time. The compounds identified can be also used as biomarkers especially for T. elatum because of the little research has been published for this species. Chromatographic profile of the stem bark reveals high predominance of alcohols and triterpenoids. Therefore, stem bark of T. elatum may be considered a source of important phytochemicals with bioactive properties to be explored for pharmaceutical applications.

\section{REFERENCES}

Acosta de la Luz, L.L., Rodríguez Ferradá, C.A. (2006). Plantas medicinales. Bases para una producción sostenible. Agrinfor, Impresiones MINAG; 124-125.La Habana, Cuba.

François-Haugrin, F., Monan, M., Nossin, E., Marcelin, O. and Smith-Ravin, J. (2016) Antioxidant Activity of an Isomer of Gossypitrin (Gossypetin-3'-O-glucoside) Isolated from Petals of Talipariti elatum Sw, and 
Determination of Total Phenolic Content of the Total Flower.Journal of Pharmacognosy and Phytochemistry 2016; 5(5): 200-208.

Gómez E. (2017). "Evaluación farmacognóstica preliminar de la corteza de Talipariti elatum Sw. (Fryxell) Malvaceae". Tesis en opción al título de Licenciado en Ciencias Farmacéuticas. Instituto de Farmacia y Alimentos. Universidad de La Habana, Cuba.

Roig, J. T. (2014). Plantas medicinales, aromáticas o venenosas de Cuba. Editorial Científico Técnica, La Habana, Cuba, 618-619.

Rohloff Jens. (2015). Analysis of Phenolic and Cyclic Compounds in Plants Using Derivatization Techniques in Combination with GC-MS-Based Metabolite Profiling. Molecules 2015, 20, 3431-3462; doi:10.3390/molecules20023431

WangMei, Jianping Zhao, BharathiAvula, Yan-Hong Wang, Cristina Avonto, Amar G. Chittiboyina, Jon F. Parcher, and Ikhlas A. Khan. (2014). High Resolution GC/MS Analysis of Ginkgolic Acids in Ginkgo biloba Plants, Extracts, and Dietary Supplements Using the Agilent 5975C Series GC/MSD. J. Agric. Food Chem. 62, 12103-12111 (2014).

Yaque, J.G., Cuéllar, A., Gaysinski, M., Monan, M., Nossin, E. and François-Haugrin, F. (2016) New Reported Flavonol Characterized by NMR from the Petals of Talipariti elatum S. w. in Cuba. American Journal of Plant Sciences, 7, 1564-1569.

Yun Zhu, Lulu Zhao, Xiangfei Wang, Peng Li. (2016). Pharmacognostical and phytochemical studies of Viola tianschanicaMaxim. - An Uyghur ethnomedicinal plant. Journal of Pharmacy \& Pharmacognosy Research, 4 (3), 95-106 ISSN 0719-4250

Citation: J. González et al., " New Chemical Compounds Isolated from the Stem Bark of Talipariti Elatum Sw. in Cuba ", International Journal of Advanced Research in Botany, vol. 4, no. 1, p. 14-18, 2018. http://dx.doi.org/10.20431/2455-4316.0401003

Copyright: (C) 2018 Authors. This is an open-access article distributed under the terms of the Creative Commons Attribution License, which permits unrestricted use, distribution, and reproduction in any medium, provided the original author and source are credited. 